\title{
Benzodiazepine Use Among Patients in a Methadone Treatment For Opioid Dependence: Findings of a Cross-sectional Study
}

Oliveira C. ${ }^{1}$, Filipe R. ${ }^{2}$, Carvalho M. ${ }^{3}$, Maia M. ${ }^{3}$, Sampaio L. ${ }^{3}$, Leme G. ${ }^{3}$, Meira J. ${ }^{3}$, Teixeira L. ${ }^{3}$, Rodrigues J. ${ }^{3}$, Machado C. ${ }^{3}$, FiuzaC. ${ }^{3}$, Nunes

I. ${ }^{3}$, Tavares. J. ${ }^{3}$

${ }^{1}$ Psychiatry Department, Hospital Prof. Dr. Fernando Fonseca, Amadora, Portugal; ${ }^{2}$ Public Health Unit, Health Group Unit of Western Lisbon and Oeiras, Oeiras, Portugal; ${ }^{3}$ Drug Adiction Treatment Center, Agualva-Cacém, Portugal

\section{INTRODUCTION}

Portugal has one of the highest rates of benzodiazepine's (BZD) consumption in Europe ${ }^{1-5}$. Although the combination of methadone with BZD is generally not recommended, the prevalence use of BZD in methadone-treated patients is still high (46.5-51.5\%) ${ }^{6-8}$. In the substitution programs with opioid agonists, it is found that BZD users have poor adherence and response to substitution treatment, leading to a worse psychosocial and rehabilitative prognosis ${ }^{9}$.

\section{OBJECTIVES}

This study aims to characterize the prevalence and patterning of BZD consumption in a methadone treatment programme.

\section{METHODS}

We conducted a cross-sectional study involving 171 patients treated with methadone in the Agualva-Cacém Drug Addiction Treatment Unit. A descriptive analysis was made of the BZD use characteristics.

\section{RESULTS}

- The prevalence of BZD consumption was $\mathbf{2 4 . 6 \%}(\mathrm{n}=\mathbf{4 2})$ but $\mathbf{7 0 . 2 \%}(\mathrm{n}=120)$ had a history of lifelong BZD regular use;

- Among the BZD users, $\mathbf{8 5 . 7 \%}$ had a regular use (>3days/week), and $\mathbf{8 1 \%}$ took one BZD type.

- The most prescribed BZD was Diazepam (25.9\%).

- The BZD were obtained with a medical prescription (47.6\%) or on the black market (44.2\%). The main reasons for BZD intake were the hypnotic (27.0\%) and anxiolytic (24.7\%) effects.

- Although almost $\mathbf{2 / 3}$ of the BZD users considers themselves as having a BZD dependency, $\mathbf{6 1 . 9 \%}$ of those patients had a high level of motivation to stop the BZD intake.

- The prevalence of BZD consumption at the programme admission was $49.7 \%$ ( $n=85)$. Of these, $50.6 \%$ stopped, $32.9 \%$ diminished the BZD use, $10.6 \%$ maintained the BZD dose and only $5.9 \%$ increased the dose.

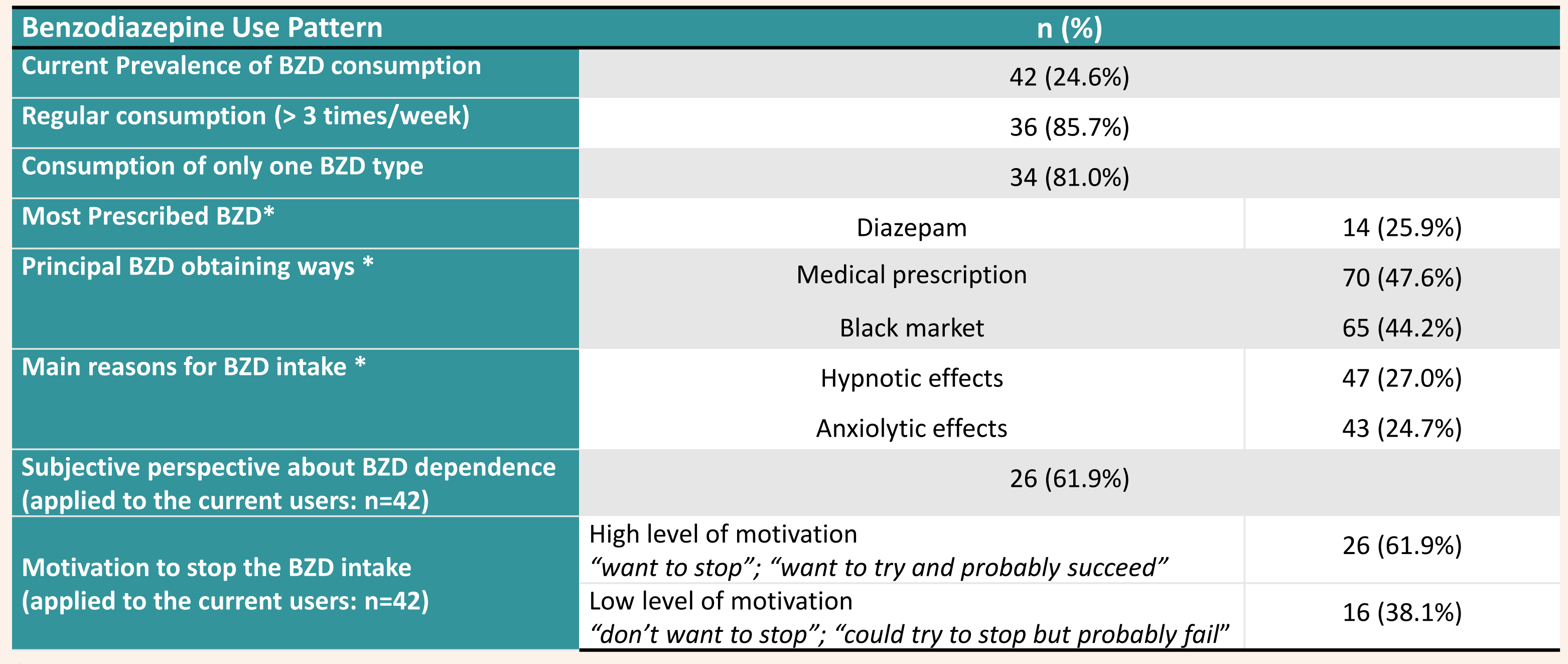

*Could select more than one option.

Table 1. Current Benzodiazepine Use Pattern

\section{CONCLUSION}

These study findings, and as explained by the international literature, show that BZD intake seems to the related with worst clinical and psychiatric outcomes. Our results showed that being supported by an methadone programme, and adequately treated, reduce the BZD intake in half of the cases.

\section{REFERENCES :}

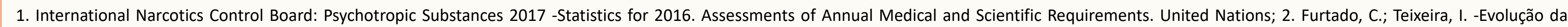

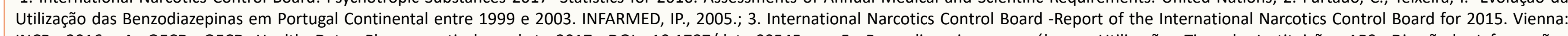

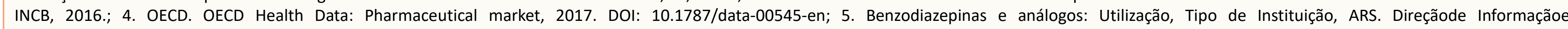

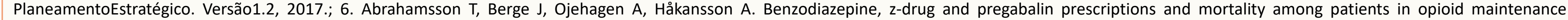

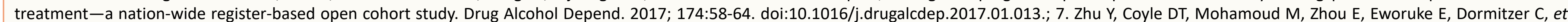

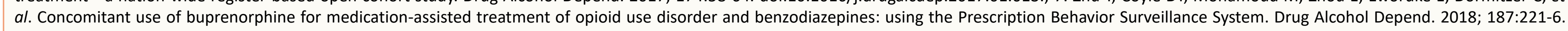

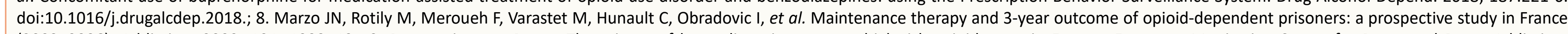

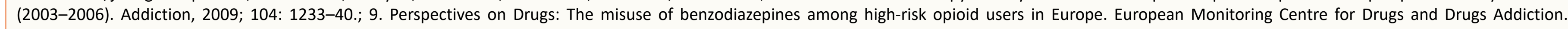
Updated 14.11.2018 